\section{Tratamento cirúrgico de lesões orais e faciais causadas por projétil balístico em cão da raça Pit Bull: relato de caso}

\author{
Surgical treatment of ballistic oral and facial lesions in a Pit Bull \\ dog: a case report
}

\begin{abstract}
Jose Ricardo Pachaly ${ }^{12}$, Rafael Santos Tramontin ${ }^{3}$, Ana Maria Quessada ${ }^{*}$, Salviano Tramontin Belettini³, Dalila Soares de Paula ${ }^{4}$, Juliano Bortolo De Conti ${ }^{5}$, Ramiro Darriba Vasconcelos ${ }^{2}$, Diogo Fernandes Giovanelli ${ }^{2}$ \& Evandra Maria Voltarelli-Pachaly²

'Médicos veterinários, Professores. Programa de Pós-graduação em Ciência Animal - PPGCA, Universidade Paranaense UNIPAR, Umuarama, PR, Brasil

2Médicos veterinários. Instituto Brasileiro de Especialidades em Medicina Veterinária - ESPECIALVET, Maringá, PR, Brasil

${ }^{3}$ Médicos veterinários, Doutorandos. Programa de Pós-graduação em Ciência Animal - PPGCA, Universidade Paranaense UNIPAR, Umuarama, PR, Brasil

${ }^{4}$ Médicos veterinários, Professores. Curso de Medicina Veterinária, Universidade Paranaense - UNIPAR, Umuarama, PR, Brasil

${ }^{5}$ Médico veterinário, Professor. Curso de Medicina Veterinária, Universidade Estadual de Maringá - UEM, Umuarama, PR, Brasil
\end{abstract}

\section{Resumo}

Os ferimentos causados por arma de fogo em cães costumam provocar lesões severas e podem ser fatais. A avaliação clínica é fundamental para a averiguação da trajetória do projétil, bem como seus efeitos e os danos sofridos pelo paciente. Este artigo descreve as características de um complexo ferimento facial em um cão da raça Pit Bull, causado por projétil balístico. O exame radiográfico confirmou a presença do projétil, que perfurou a face na região maxilar esquerda, penetrando a região nasal e causando avulsão de quatro dentes. O projétil seguiu em direção à rama mandibular esquerda, onde deixou resíduos de chumbo e ricocheteou, instalando-se definitivamente na porção médio-lateral da base da língua, de onde foi removido cirurgicamente. O impacto afetou os três dentes molares inferiores esquerdos, fraturando os dois primeiros, e seus fragmentos e raízes tiveram de ser removidos cirurgicamente. O paciente foi acompanhado ao longo de um ano, evoluindo para plena recuperação já no primeiro mês após a intervenção.

Palavras-chave: canino, cirurgia buco-maxilo-facial veterinária, odontoestomatologia veterinária, perícia forense veterinária, trauma.

\begin{abstract}
Trauma caused by ballistic projectiles in dogs causes severe lesions and may be fatal. Clinical evaluation is very important to verify the projectile path, its effects and damage caused to the patient. This paper describes the characteristics of a complex facial wound in a Pit Bull, caused by a ballistic projectile. Radiographic examination confirmed the presence of the projectile, transfixing the left maxilla, penetrating the nasal region, and causing avulsion of four teeth. The projectile followed to left mandible, left lead residues and came back to the tongue, remaining in the mediolateral part of its basis, being surgically removed. The impact affected the three left molar teeth, which remaining fragments and roots needed to be extracted. The patient recovered within one month and the follow-up period persisted for one year, without intercurrences.
\end{abstract}

Keywords: canine, veterinary oral and maxillofacial surgery, veterinary dentistry, veterinary forensic investigation, trauma.

\section{Introdução}

Atualmente, uma das maiores preocupações da sociedade na segurança pública se refere à disseminação da violência, sendo consenso que um dos principais agravantes desse quadro é o uso crescente e descontrolado de armas de fogo. Tal uso leva a diversos tipos de traumatismos e torna necessário o estudo das características das lesões causadas pelos projéteis das armas de fogo (Heard, 2008). \section{BJ M

Como citar: Pachaly, J. R., Tramontin, R. S., Quessada, A. M., Belettini, S. T., Paula, D. S., Conti, J. B., Vasconcelos, R. D., Giovanelli, D. F., \& Voltarelli-Pachaly, E. M. (2017). Tratamento cirúrgico de lesões orais e faciais causadas por projétil balístico em cão da raça Pit Bull: relato de caso. Brazilian Journal of Veterinary Medicine, 39(2), 138-145. doi: 10.29374/2527-2179. bjvm024916

Fonte de financiamento: Unipar (Universidade Paranaense).

Conflito de interesses: Os autores declaram não haver conflito de interesses que precisam ser informados.

Recebido: Dezembro 01, 2015.

Aceito: Maio 02, 2016.

O estudo foi realizado no Hospital Veterinário da Universidade Paranaense - UNIPAR, Umuarama, PR, Brasil.

\section{*Correspondência}

Ana Maria Quessada

Programa de Pós-graduação em Ciência Animal - PPGCA, Universidade Paranaense UNIPAR

Praça Mascarenhas de Moraes, 4282, Zona III CEP 87502-210 - Umuarama (PR), Brasil

E-mail: quessadavet@gmail.com

Copyright Pachaly et al. Este é um artigo publicado em acesso aberto (Open Access) sob a licença Creative Commons Attribution Non-Commercial, que permite uso, distribuição e reprodução em qualque meio, sem restrições desde que sem fins comerciais e que o trabalho original seja corretamente citado. 
No momento de um disparo são ejetados pela arma, além do projétil, diversos resíduos sólidos (provenientes do projétil e da detonação da mistura iniciadora e da pólvora) e produtos gasosos (monóxido e dióxido de carbono, vapor de água, óxido de nitrogênio e outros). Parte desses resíduos sólidos permanece na própria arma, porém o restante é projetado para fora, atingindo mãos, braços, cabelos e roupas do atirador, além de se espalhar pela cena do disparo, tornando possível a identificação do atirador (Reis et al., 2004; Heard, 2008).

Um aspecto pouco analisado na literatura se relaciona ao comportamento do projétil dentro dos tecidos e ao tratamento posterior das lesões ósseas. Os detalhes mais significativos são a velocidade e o peso do projétil, sendo que a destruição dos tecidos depende da energia desprendida pelo projétil. Um projétil é considerado de alta velocidade quando alcança mais de 600 metros por segundo (m/s), e de baixa velocidade quando atinge menos de $500 \mathrm{~m} / \mathrm{s}$. Os projéteis de diferentes calibres desenvolvem diferentes velocidades. Por exemplo, o calibre.38SPL desenvolve $349 \mathrm{~m} / \mathrm{s}$, o .22 desenvolve $308 \mathrm{~m} / \mathrm{s}$ e o.45ACP (Automatic Colt Pistol) chega a 277m/s. Este último, entretanto, tem maior poder de neutralização do atingido pelo disparo, ou seja, o seu poder de parada (stopping power) é maior, fator interessante em armas de defesa. O poder de parada está relacionado ao momento (instante do impacto) do projétil e não à sua energia, de forma que calibre e peso do projétil são mais importantes que sua velocidade (Domit, 1997).

Ao encontrar um corpo, a energia do projétil vai sendo absorvida no trajeto pelo interior desse corpo, sendo que a extensão e os danos dependem da quantidade e tipo de tecido atingido. Assim, o projétil provoca um pequeno orifício de entrada e destruição maciça ao longo do seu trajeto (Ferreira, 2014).

Ferimentos por armas de fogo podem resultar em consequências estéticas e funcionais devastadoras para as vítimas desse trauma e vários fatores imprevisíveis influenciam esse tipo de ferimento, tornando complexo o atendimento inicial e o tratamento definitivo (Morais et al., 2010).

Na prática odontológica veterinária, é fundamental que se compreenda a necessidade de se evitar a extração dental, procurando manter os dentes na boca dos animais mediante o emprego de técnicas conservadoras. A extração dental causa reabsorção e remodelação das estruturas ósseas de suporte, fragilizando o crânio. Assim, sempre que possivvel, deve-se preservar a dentição, mantendo a integridade do aparelho mastigatório e garantindo a eficiência do processamento dos alimentos (Pachaly, 2006; Pachaly \& Voltarelli-Pachaly, 2014). As principais indicações para extração dental envolvem as situações em que é impossível qualquer tipo de tratamento conservador. Essas situações incluem enfermidade periodontal muito grave, abscessos periapicais (com ou sem fístula) e fraturas dentais com grave necrose pulpar (Pachaly \& Voltarelli-Pachaly, 2014).

A radiologia é um excelente meio de diagnóstico para exame e estudo das estruturas orais nos animais, mas, para atingir maior qualidade e valor diagnóstico das imagens, geralmente é necessário que o paciente seja sedado ou anestesiado (San Román, 1999).

A anestesia injetável empregando associações de agentes dissociativos a agonistas de receptores adrenérgicos e benzodiazepínicos é muito empregada em medicina veterinária. A associação de Zoletil ${ }^{\oplus}$ (tiletamina + zolazepam), xilazina e atropina, denominada "ZAX-50", vem sendo utilizada em diversas espécies de mamíferos. Os efeitos dessa associação farmacológica induzem estado de analgesia, miorrelaxamento e imobilidade capaz de possibilitar a realização de procedimentos médicos, cirúrgicos e odontológicos (Pachaly et al., 2011).

O presente relato tem o objetivo de descrever as características de um complexo ferimento facial em um cão da raça Pit Bull, causado por projétil balístico.

\section{Histórico}

Foi atendido em um hospital veterinário universitário um cão macho da raça Pit Bull, não castrado, com oito anos de idade e massa corporal de $29,6 \mathrm{~kg}$. A queixa principal era de anorexia e sangramento oral, após histórico de fuga recente.

Na avaliação inicial, os parâmetros vitais se encontravam normais, mas o paciente apresentava dor à manipulação da cavidade oral. Havia sangramento e presença de um ferimento perfurante na região maxilar esquerda, transfixando a região nasal (Figura 1A).

Sob a suspeita clínica de ferimento por projétil balístico, indicou-se a contenção farmacológica, para realização de exame físico judicioso e avaliação radiográfica. Para isso, o cão recebeu por injeção 


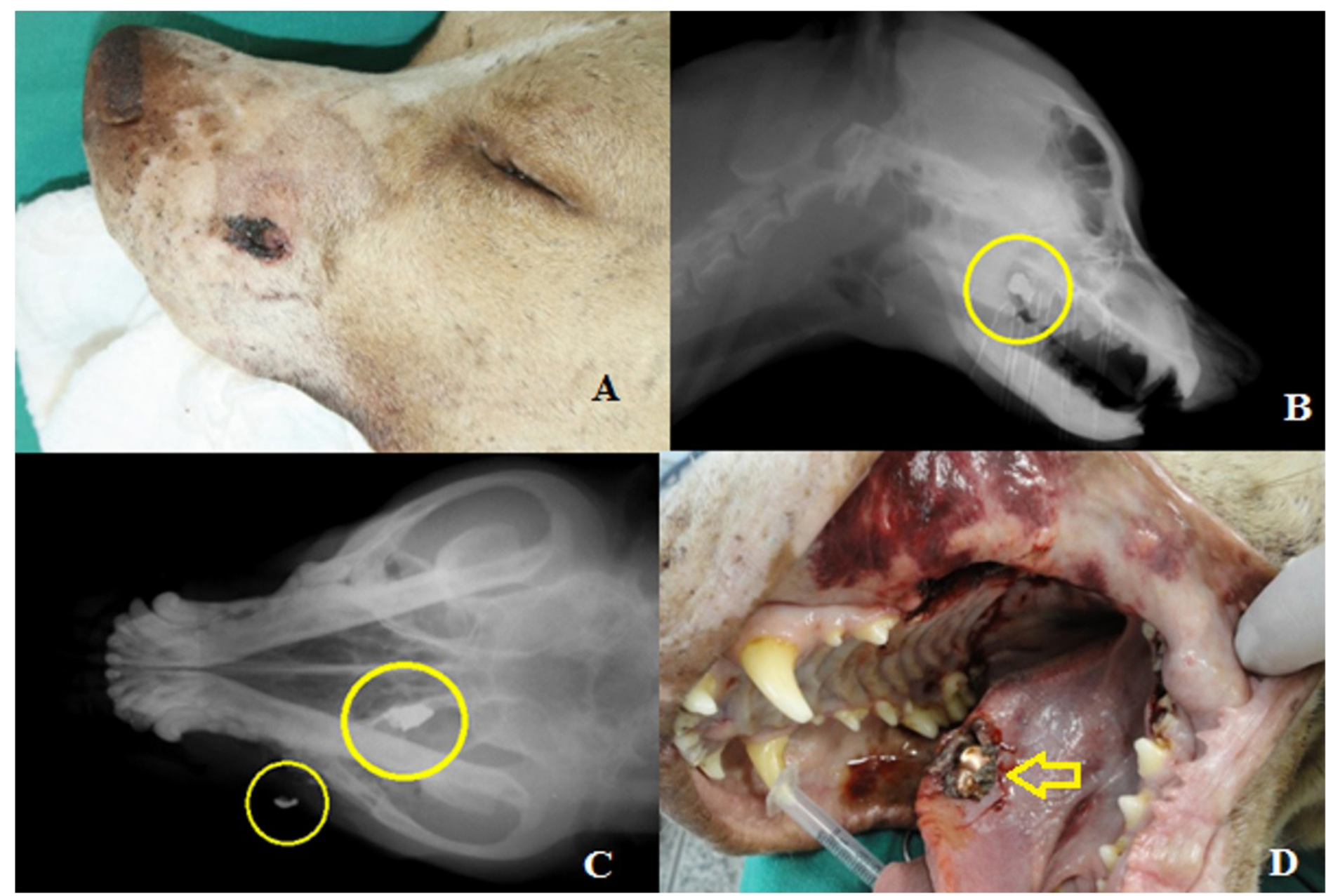

Figura 1. Imagens da cabeça de um cão cão macho da raça Pit Bull com oito anos de idade e29,6 kg de massa corporal, apresentado com anorexia e sangramento oral. A: Ferimento perfurante na região maxilar esquerda. B: Radiografia lateral evidenciando estrutura radiopaca (círculo amarelo) compatível com fragmento de projetil balístico. C: Radiografia dorso-ventral evidenciando estruturas radiopacas (círculos amarelos) compatíveis com fragmentos de projétil balístico. D: Ferimento perfurante na região da maxila esquerda e lesão na borda médio-lateral esquerda da língua, evidenciando estrutura metálica (seta amarela) identificada como um projétil balístico. (Fonte: autores).

intramuscular (IM) a associação denominada "ZAX-50" (zolazepam, tiletamina, atropina exilazina), em doses calculadas por meio de extrapolação alométrica interespecífica (Pachaly et al., 2011).

Ao exame físico observou-se avulsão dos dentes terceiro pré-molar superior esquerdo (3PMSE), quarto pré-molar superior esquerdo (4PMSE), primeiro molar superior esquerdo (1MSE) e segundo molar superior esquerdo (2MSE). Também havia um ferimento lacerante na região médio-lateral esquerda da língua, fraturas coronais nos dentes primeiro molar inferior esquerdo (1MIE) e segundo molar inferior esquerdo (2MIE) e abalo radicular no terceiro molar inferior esquerdo (3MIE).

As imagens confirmaram a suspeita, sendo que a radiografia craniana latero-lateral (Figura 1B) evidenciou estrutura radiopaca compatível com fragmento de projetil balístico, em área de projeção de dentes molares superiores e base da língua. A radiografia dorso-ventral (Figura 1C) permitiu observar estruturas radiopacas compatíveis com fragmentos de projétil balístico, em área de projeção da cavidade nasal esquerda e região de tecidos moles de face (região labial esquerda).

Após a avaliação radiográfica, novo exame físico da cavidade oral evidenciou perfuração na região maxilar esquerda, pela qual passou o projétil que havia penetrado a região nasal da face do paciente. Foi observado um ferimento perfurante na região da maxila esquerda e uma lesão na superfície médio-lateral esquerda da língua, onde se evidenciou a presença de estrutura metálica identificada como um projétil balístico (Figura 1D). 
A interpretação da ação do projétil foi fundamental para a planificação do tratamento cirúrgico. Em seu trajeto, ele causou a avulsão dos dentes 3PMSE, 4PMSE, 1MSE e 2MSE e o ferimento lacerante na região médio-lateral esquerda da língua, bem como as fratura coronais nos dentes 1MIE e 2MIE e o abalo radicular no 3MIE, ricocheteando na rama mandibular esquerda e instalando-se definitivamente na língua.

O paciente persistiu anestesiado com ZAX-50 para realização do tratamento cirúrgico, durante o qual foi necessário extrair os fragmentos dos dentes avulsionados e fraturados, bem como remover o projétil localizado na língua.

Inicialmente foi realizada a remoção do corpo estranho metálico localizado na porção médio-lateral esquerda da face inferior da língua (Figura 1D), mediante tração com uma pinça hemostática (Figura 2A). Depois disso, a lesão cavitária foi curetada com lima de Seldin (Figuras 2B e 2C). A lesão lingual não foi suturada, sendo mantida aberta para permitir drenagem e cicatrização por segunda intenção (Figura 2D).

Após a resolução da lesão lingual, procedeu-se à extração dos fragmentos de dentes avulsionados e remoção de fragmentos ósseos da região maxilar esquerda empregando-se alavanca, boticão e cinzel cirúrgico (Figura 2E). Foi detectado um grande fragmento ósseo maxilar, completamente desconectado da ossatura adjacente, o qual foi removido por tração com um boticão Standard (Figura 2F). Após a extração dos dentes e remoção dos fragmentos ósseos foi possível avaliar a lesão da região maxilar esquerda, constatando-se que era muito extensa e havia provocado comunicação oronasal (Figura 2G). Realizou-se a seguir curetagem óssea com lima de Seldin, o que evidenciou o trajeto do projétil através da maxila (Figura 2H).

A sutura da lesão da região maxilar esquerda iniciou-se nas extremidades cranial e caudal da ferida, usando-se fio de poliglactina 910 (Ácido poliglicólico, Shalon Fios Cirúrgicos, São Luiz de Montes Belos - GO) \#2.0 e alternando-se pontos simples isolados e pontos de Wolf (Figura 2I).

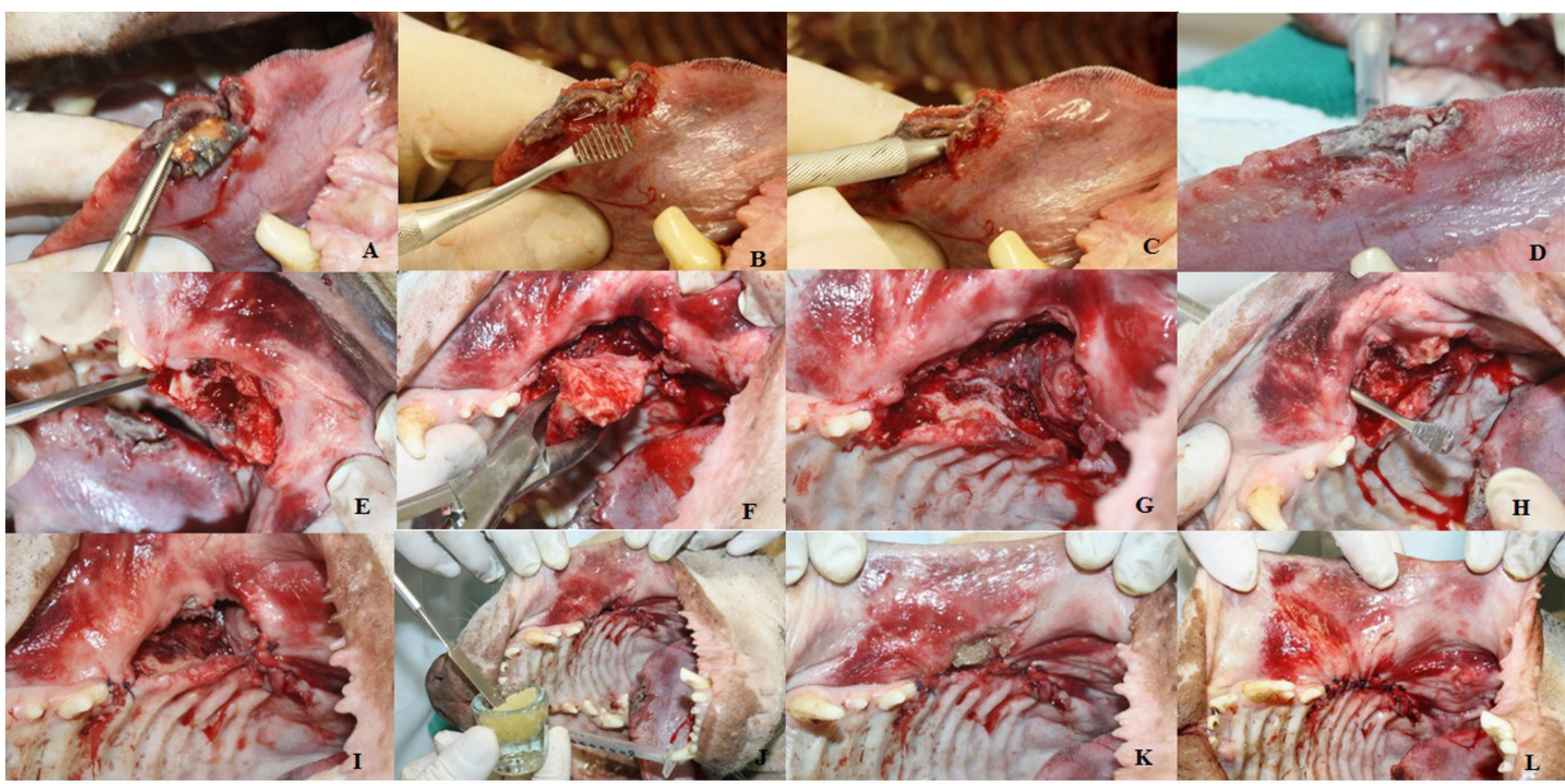

Figura 2. Imagens da cavidade oral de um cão cão macho da raça Pit Bull com oito anos de idade e 29,6 kg de massa corporal, ferido na face por um disparo de arma de fogo. A: remoção do projétil balístico da língua com pinça hemostática. B: Curetagem da lesão lingual com lima de Seldin. C: Lima de Seldin introduzida na lesão lingual, durante sua curetagem. D: Porção médio-lateral esquerda da face inferior da língua, após remoção do projétil balístico e curetagem. E: Extração de fragmentos de dentes avulsionados e remoção de fragmentos ósseos na região maxilar esquerda. F: Remoção de um grande fragmento ósseo, usando boticão Standard. G: Lesão da região maxilar esquerda após a extração dos dentes avulsionados e remoção dos fragmentos ósseos. H: Comunicação oro-nasal devida ao trajeto do projétil balístico através da maxila. I: Início da sutura da lesão da região maxilar esquerda. J: Início da obliteração da lesão com massa formada pela mistura de gelatina e gentamicina. K: Obliteração completa da lesão com a mesma massa. L: Sutura da lesão após sua obliteração. 
Tendo em vista a profundidade do defeito ósseo remanescente e a necessidade de obliterá-lo adequadamente, foi usada uma pasta preparada à base de gelatina comestível granulada (Gelatina, Dr. Oetker ${ }^{\circledR}$, São Paulo - SP) e solução de gentamicina (Gentocin ${ }^{\circledR}$, Lab. MSD, São Paulo - SP) a 4\% para obliterar a cavidade (Figuras 2J e 2K), conforme as indicações de Pachaly \& Voltarelli-Pachaly (2014). A área assim obliterada foi fechada usando-se mesmo fio e padrão de sutura (Figura 2L).

Finalmente, a conduta terapêutica foi direcionada aos dentes molares da arcada inferior esquerda (1MIE, 2MIE e 3MIE) (Figura 3A), que foram extraídos mediante luxação radicular com uso de martelo e cinzel (Figura 3B), até plena liberação das respectivas cavidades alveolares (Figura 3C). A seguir, realizou-se aplainamento dos alvéolos dentais empregando-se broca cirúrgica (Zekrya 151, Maillefer-Dentsply, São Paulo - SP) de 28mm montada em caneta de alta rotação (Figura 3D), até que não restasse nenhuma imperfeição capaz de reter material contaminante. Tais cavidades ósseas foram deixadas abertas, para permitir drenagem e cicatrização por segunda intenção.

No período pós-operatório foi administrado enrofloxacina IM, 10,0 mg/kg (Baytril 10\% ${ }^{\circledR}$, Lab. Bayer, São Paulo - SP) durante cinco dias e cetoprofeno IM, 2,0 mg/kg (Ketofen ${ }^{\circledR}$, Lab, Merial, São Paulo - SP.) durante três dias.

O material metálico removido da língua (Figura 3E) foi periciado, identificando-se projétil balístico encamisado de calibre $6.35 \mathrm{~mm}$ Browning (também conhecido como calibre .25ACP ou calibre .25AUTO), deformado pelo impacto contra o alvo.

Doze dias após o tratamento cirúrgico o paciente foi reavaliado, encontrando-se em boas condições físicas, sem sinais de infecção, com cicatrização parcial do ferimento cutâneo perfurante localizado na região maxilar esquerda (Figura $3 \mathrm{~F}$ ), tendo retornado plenamente às funções normais. Foi novamente anestesiado de acordo com o mesmo protocolo, para avaliação clínica

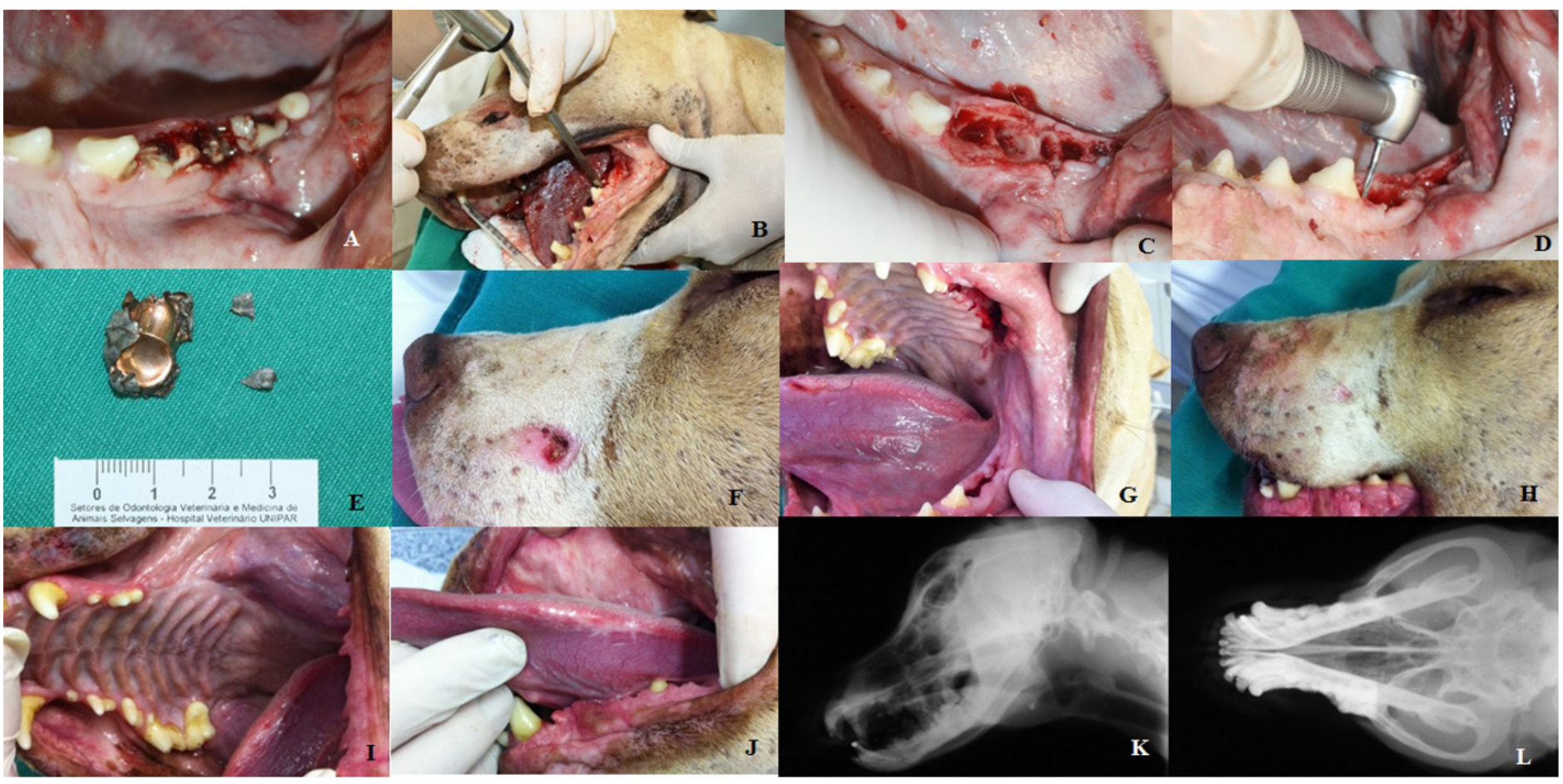

Figura 3. Imagens da cabeça e cavidade oral de um cão cão macho da raça Pit Bull com oito anos de idade e 29,6 kg de massa corporal, ferido na face por um disparo de arma de fogo. A: fragmentos das coroas dos dois primeiros dentes molares da arcada inferior esquerda, fraturados pelo impacto do projétil balístico. B: Uso de cinzel e martelo no procedimento de luxação radicular, durante a extração dos dentes fraturados. C: Arcada inferior esquerda, com destaque para os alvéolos dentais, após a extração dos dentes. D: Aplainamento dos alvéolos dentais com broca cirúrgica. E: Projétil balístico deformado e alguns de seus fragmentos, retirados da língua. F: Face após o tratamento cirúrgico com cicatrização parcial do ferimento. G: Cavidade oral, 12 dias após o tratamento cirúrgico. Observa-se cicatrização parcial dos ferimentos. H: Face, 11 meses após o tratamento cirúrgico, com plena recuperação e cicatrização adequada dos ferimentos. I: Cavidade oral, 11 meses após o tratamento cirúrgico, com plena recuperação e cicatrização adequada dos ferimentos da língua e maxila. J: Detalhe da cicatrização do ferimento da língua, 11 meses após o tratamento cirúrgico. K,L: Imagens radiográficas latero-lateral e dorso-ventral do crânio, realizadas 11 meses após o tratamento cirúrgico. Observa-se ausência dos dentes extraídos, sem sinais de complicações, e ausência de fragmentos do projétil balístico. 
adequada das lesões e realização de tratamento endodôntico no dente canino inferior esquerdo, que apresentava uma fratura coronal antiga, não relacionada ao trauma balístico. Para tanto, empregou-se a técnica indicada para carnívoros selvagens por Pachaly (2006). As lesões lingual e mandibular se apresentavam em processo satisfatório de cicatrização (Figura 3G). A lesão maxilar apresentou deiscência de parte da sutura, porém já era digna de nota a condição plenamente satisfatória do defeito ósseo que fora preenchido com a mistura de gelatina e gentamicina, não se observando nenhuma depressão notória na região (Figura 3H). Os resquícios das suturas foram removidos e o paciente recebeu alta médica.

Onze meses depois, o animal retornou ao hospital para realização de outro procedimento, mostrando plena recuperação em relação às lesões buco-maxilo-faciais oriundas do trauma por projétil balístico (Figuras 3I e 3J). Radiografias cranianas realizadas em posição latero-lateral (Figura 3K) e dorso-ventral (Figura 3L) não mostraram sinais de complicações ósseas na maxila ou de comprometimento de cavidade nasal, nem evidências de fragmentos do projétil. No dente canino inferior esquerdo, submetido a tratamento endodôntico, não se verificou alteração radiográfica na região peri-apical.

\section{Discussão}

Traumas são frequentes em cães (Bentubo et al., 2007; Fighera et al., 2008), especialmente quando o animal sai à rua desacompanhado (Bentubo et al., 2007) ou foge de seu domicílio, como ocorreu neste caso. Inclusive, o proprietário não estava ciente de que o animal tinha sido vítima de disparo por arma de fogo, pois não assistiu ao evento traumático, já que o cão havia fugido. O paciente deste caso foi um cão macho não castrado, perfil da maioria dos animais que sofrem trauma em ruas e espaços públicos (Mendes \& Arias, 2012).

Não foi possível identificar o autor ou o motivo do disparo, mas a raça Pit Bull é considerada agressiva contra seres humanos (Paranhos et al., 2013) e outros cães (Mouro et al., 2009), e a maioria dos cães agressores é de machos não castrados (Mouro et al., 2009). Assim, supõe-se que o tiro que vitimou o paciente possa ter resultado de uma reação de defesa a um ataque deste cão a uma pessoa ou a outro cão acompanhado por um proprietário armado. Entretanto, há também a possibilidade de um ataque a tiro motivado por preconceito contra a raça (Valli, 2015).

Como foi feito neste caso, os exames de imagem apoiam o diagnóstico, permitindo mais segurança para avaliar lesões em ossos e tecidos moles e para localizar e pré-identificar o tipo de projétil (Pavletic \& Trout, 2006; Prado et al., 2011). Para o exame radiográfico e para o tratamento cirúrgico o paciente foi anestesiado, conforme se recomenda na literatura (Bar-Am et al. 2008, Prado et al., 2011). O protocolo empregado foi adequado ao propósito, corroborando dados da literatura que indicam a associação denominada "ZAX-50" na contenção farmacológica de primatas cercopitecíneos e outros mamíferos (Pachaly et al., 2011).

Com base no percurso do projétil, ferimentos à bala podem ser classificados como perfurantes (com uma entrada e uma saída), cegos (penetrante e sem saída) e de contato (quando a pele e tecidos abaixo são destruídos sem formação de canal) (Felsmann et al., 2014). Neste caso o ferimento pode ser classificado como cego, pois foi possível observar que o projétil recuperado criou um ferimento de entrada na maxila do animal, porém não existia um ferimento de saída no corpo do paciente.

Levando-se em consideração que um projétil cria um canal em feridas perfurantes e cegas (Felsmann et al., 2014), pode-se inferir que o projétil que atingiu o paciente entrou pela região maxilar esquerda formando um canal e penetrando a região nasal da face, seguiu trajeto em direção à rama mandibular esquerda, onde ricocheteou, instalando-se definitivamente na língua. A formação do canal originou comunicação oro-nasal que foi corrigida cirurgicamente, como indicado na literatura (Bolson \& Pachaly, 2004).

Fraturas cranianas de origem traumática são comuns em cães (Christensen et al., 2015), sendo que fraturas de maxila como a observada neste caso representam 3 a $6 \%$ de todas as fraturas (Prado et al., 2011).

A ação do projétil também foi a causa do ferimento lacerante na região médio-lateral esquerda da língua, da avulsão dos dentes 3PMSE, 4PMSE, 1MSE e 2MSE, bem como de fraturas coronais nos dentes 1MIE e2MIE e de abalo radicular no 3MIE. Christensen et al. (2015) comentam que, em traumas cranianos de origem balística, podem ocorrer fraturas dentárias e, devido a tais fraturas 
dentárias, foi necessária a exodontia, que é a cirurgia oral mais praticada em cães e gatos (Roza, 2004). A extração dos dentes molares inferiores esquerdos seguiu os passos preconizados por Pachaly (2006) e Pachaly \& Voltarelli-Pachaly (2014) e foi bem sucedida.

A sutura dos tecidos moles e fibrosos da maxila seguiu o indicado para situações de exodontia em carnívoros selvagens, empregando fio de poliglactina 910 e pontos isolados ou padrão de Wolf (Pachaly \& Voltarelli-Pachaly, 2014).

Ouso de gelatina comestível sem sabor como elemento substituto das tradicionais e dispendiosas esponjas cirúrgicas de colágeno, utilizadas em odontologia (Faria et al., 2010) mostrou ser uma eficiente alternativa de baixo custo para obliteração de ferimentos elesões cavitárias. Nesse método, preconizado por Pachaly \& Voltarelli-Pachaly (2014), a gelatina granulada é misturada com uma solução injetável de gentamicina a 4\% ou 5\%, sendo espatulada até formar um gel úmido que é usado para preencher as lesões. Neste cão o resultado foi positivo, como já observado anteriormente pelos autores em carnívoros selvagens, demonstrando potencial para emprego rotineiro na reposição do volume de cavidades ósseas. Enfatiza-se o baixo custo, a facilidade de obtenção dos materiais empregados e a difusibilidade tópica da gentamicina, que contribui para a redução dos riscos de infecção localizada (Pachaly \& Voltarelli-Pachaly, 2014).

Os medicamentos utilizados no pós-operatório (antibióticos e anti-inflamatórios) fazem parte da rotina odontológica em carnívoros domésticos (Roza, 2004) e selvagens (Pachaly \& VoltarelliPachaly, 2014), sendo também indicados em ferimentos por arma de fogo (Felsmann et al., 2014) e traumas buco-maxilo-faciais (Christensen et al., 2015).

Neste caso, observou-se recuperação satisfatória do paciente e retorno às funções normais, como é esperado em lesões dessa natureza, quando não ocorre grande envolvimento sistêmico (Felsmann et al., 2014; Christensen et al., 2015).

Os dados obtidos pela análise do trajeto do projétil demonstram que o mesmo não tinha grande monta de energia, ou seja, tinha pouco poder de parada (Heard, 2013). Outro aspecto que aponta para a pouca energia do projétil foi sua extrema deformação, indicando que apesar do disparo ter sido realizado a curta distância, ele não causou ferimento de saída por ser incapaz de transfixar o alvo (Heard, 2013). Os dados obtidos pela análise do projétil permitem afirmar com segurança que se tratava de projétil disparado por uma pistola calibre $6.35 \mathrm{~mm}$. Esse calibre, de pequenas dimensões e pouca energia, é geralmente empregado em pequenas armas curtas, as chamadas "armas de bolso" (Gazinhato, 1997; Heard, 2008; 2013).

\section{Conclusão}

Neste caso, os procedimentos diagnósticos e terapêuticos foram bem sucedidos, proporcionando condições normais de vida ao paciente, sem prejuízo para suas funções orgânicas.

O aumento da violência nas cidades brasileiras, associado ao uso indiscriminado de armas de fogo, gera crescentes possibilidades de traumatismos por projéteis balísticos em animais de estimação, especialmente cães machos de grande porte. Dessa maneira, clínicas e hospitais veterinários devem estar preparados para atendimento desse tipo de trauma.

\section{Referências}

Bar-Am, Y., Pollard, R. E., Kass, P. H., \& Verstraete, F. J. M. (2008). The diagnostic yield of conventional radiographs and computed tomography in dogs and cats with maxillofacial trauma. Veterinary Surgery, 37(3), 294-299. http://dx.doi.org/10.1111/j.1532-950X.2008.00380.x. PMid:18394078.

Bentubo, H. D. L., Tomaz, M. A., Bondan, E. F., \& Lallo, M. A. (2007). Expectativa de vida e causas de morte em cães na área metropolitana de São Paulo (Brasil). Ciência Rural, 37(4), 1021-1026. http://dx.doi.org/10.1590/ S0103-84782007000400016.

Bolson, J., \& Pachaly, J. R. (2004). Fístula oronasal em cães (Canis familiaris Linnaeus, 1758). Revisão da literatura. Arquivos de Ciências Veterinárias e Zoologia da UNIPAR, 7, 53-56.

Christensen, J., Sawatari, Y., \& Peleg, M. (2015). High-energy traumatic maxillofacial injury. The Journal of Craniofacial Surgery, 26(5), 1487-1491. http://dx.doi.org/10.1097/sCS.0000000000001789. PMid:26114523.

Domit K. Traumatismo músculo-esquelético por projétil de arma de fogo. (1997). Revista Brasileira de Ortopedia, 32(10), 827-831

Faria, M. C., Villa, N., Carbonel, A. A. F., Hadad, S., \& Faraco, F. N. (2010). Análise histológica da lesão óssea de mandíbula de coelho após aplicação local de cloreto de estrôncio. Revista Gaucha de Odontologia, 58, 487-490. 
Felsmann, M. Z., Felsmann, M., Szarek, J., \& Babińska, I. (2014). A review of firearms, projectile and gunshot wounds in animals. Pakistan Veterinary Journal, 34, 279-287.

Ferreira, R. Traumatismo provocado por projétil de arma de fogo (PAF). Recuperado em 14 Dezembro 2014, de www.tudolevaapericia.blogspot.com.br

Fighera, R. A., Souza, T. M., Silva, M. C., Brum, J. S., Graça, D. L., Kommers, G. D., Irigoyen, L. F., \& Barros, C. S. L. (2008). Causas de morte e razões para eutanásia de cães da Mesorregião do Centro Ocidental Rio-Grandense (19652004). Pesquisa Veterinária Brasileira, 28(4), 223-230. http://dx.doi.org/10.1590/50100-736X2008000400005.

Gazinhato, L. (1997). Catálogo Magnum 97. São Paulo: Magnum.

Heard, B. J. (2008). Handbook of firearms and ballistics: examining and interpreting forensic evidence. (2nd ed.) Hoboken: Wiley. http://dx.doi.org/10.1002/9780470694589.

Heard, B. J. (2013). Forensic ballistics in court: Interpretation and presentation of firearms evidence. Hoboken: Wiley-Blacwell.

Mendes, D. S., \& Arias, M. V. B. (2012). Traumatismo da medula espinhal em cães e gatos: estudo prospectivo de 57 casos. Pesquisa Veterinária Brasileira, 32(12), 1304-1312. http://dx.doi.org/10.1590/S0100-736X2012001200015.

Morais, H. H. A., Carvalho, R. W. F., Rocha, N. S., Vasconcelos, B. C. D. E., \& Vasconcellos, R. J. D. H. (2010). Tratamento imediato de fratura de mandíbula por projétil de arma de fogo. Revista Gaucha de Odontologia, 58, 399-403.

Mouro, S., Vilela, C. L., \& Niza, M. N. E. (2009). Caracterização de agressões entre canídeos (83 casos). Revista Portuguesa de Ciências Veterinárias, 104, 61-69.

Pachaly, J. R. (2006). Odontoestomatologia em animais selvagens. In Z. S. Cubas, J. L. C. Dias \& J. C. R. Silva (Eds.), Tratado de animais selvagens - medicina veterinária (pp. 1068-1091). São Paulo: Roca.

Pachaly, J. R., \& Voltarelli-Pachaly, E. M. (2014). Periodontia e Exodontia. In Z. S. Cubas, J. L. C. Dias \& J. C. R. Silva (Eds.), Tratado de animais selvagens - medicina veterinária (2a ed., pp. 1995-2019). São Paulo: Roca.

Pachaly, J. R., Carneiro, M. R., Alberton, L. R., Belettini, S. T., Azzolini, F., Prazeres, R. F., \& Voltarelli-Pachaly, E. M. (2011). Contenção farmacológica e anestesia de campo em primatas da Família Cercopithecinae empregando a fórmula "ZAX-50" (Zoletil/50 ${ }^{\circledR}$ + atropina + xilazina). Revista Científica de Medicina Veterinaria, 9, 415-459.

Paranhos, N. T., Silva, E. A., Bernardi, F., Mendes, M. C. N. C., Junqueira, D. M. A. G., Souza, I. O. M., Albuquerque, J. O. M., Alves, J. C. M., \& Machado, M. N. P. (2013). Estudo das agressões por cães, segundo tipo de interação entre cão e vítima, e das circunstâncias motivadoras dos acidentes, município de São Paulo, 2008 a 2009. Arquivo Brasileiro de Medicina Veterinária e Zootecnia, 65(4), 1033-1040. http://dx.doi.org/10.1590/ S0102-09352013000400014.

Pavletic, M. M., \& Trout, N. J. (2006). Bullet, bite and burn wounds in dogs and cats. The Veterinary Clinics of North America. Small Animal Practice, 36(4), 873-893. http://dx.doi.org/10.1016/j.cvsm.2006.02.005. PMid:16787791.

Prado, T. D., Silva, L. A. F., Mariano, K. P., Rodrigues, L. F., Meneses, T. D., \& Roza, M. R. (2011). Técnicas de imobilização de mandíbulas de cães e gatos: revisão de literatura. Revista Científica de Medicina Veterinaria, 9, 600-605.

Reis, E. L. T., Sarkis, J. E. S., Rodrigues, C., Negrini-Neto, O., \& Viebig, S. (2004). Identificação de resíduos de disparos de arma de fogo por meio da técnica de espectrometria de massas de alta resolução com fonte de plasma indutivo. Revista Química Nova, 27, 9-413.

Roza M.R. (2004). Odontologia em pequenos animais. Rio de Janeiro: L.F. Livros.

San Román, F. (1999). Atlas de odontologia de pequenos animais. São Paulo: Manole.

Valli, R. (2015, 09 de maio). Além de maus-tratos, pit bulls têm que enfrentar o preconceito. Correio Popular. Recuperado em 12 Novembro 2015, de http://correio.rac.com.br/_conteudo/2015/05/especial_correio/ coisa_de_bicho/257598-alem-de-maus-tratos-pit-bulls-tem-que-enfrentar-o-preconceito.html 